\title{
Inhibition of COX-2 expression by topical diclofenac enhanced radiation sensitivity via enhancement of TRAIL in human prostate adenocarcinoma xenograft model
}

Takeshi Inoue, Satoshi Anai, Sayuri Onishi, Makito Miyake, Nobumichi Tanaka, Akihide Hirayama, Kiyohide Fujimoto and Yoshihiko Hirao

\begin{abstract}
Background: COX-2 inhibitors have an antitumor potential and have been verified by many researchers. Treatment of cancer cells with external stressors such as irradiation can stimulate the over-expression of COX-2 and possibly confer radiation resistance. In this study, we tested if topical diclofenac, which inhibits both COX-1 and COX-2, administration rendered prostate tumor cells sensitize to the effects of radiation.
\end{abstract}

Methods: LNCaP-COX-2 and LNCaP-Neo cells were treated with 0 to $1000 \mu \mathrm{M}$ diclofenac. Next, a clonogenic assay was performed in which cells were subjected to irradiation ( 0 to $4 \mathrm{~Gy}$ ) with or without diclofenac. COX-2 expression and other relevant molecules were measured by real-time PCR and immunohistochemistry after irradiation and diclofenac treatment. In addition, we assessed the tumor volumes of xenograft LNCaP-COX-2 cells treated with topical diclofenac with or without radiation therapy (RT).

Results: LNCaP-COX-2 and LNCaP-Neo cell lines experienced cytotoxic effects of diclofenac in a dose related manner. Clonogenic assays demonstrated that LNCaP-COX-2 cells were significantly more resistant to RT than LNCaP-Neo cells. Furthermore, the addition of diclofenac sensitized LNCaP-COX-2 not but LNCaP-Neo cells to the cytocidal effects of radiation. In LNCaP-COX-2 cells, diclofenac enhanced radiation-induced apoptosis compared with RT alone. This phenomenon might be attributed to enhancement of RT-induced TRAIL expression as demonstrated by real-time PCR analysis. Lastly, tumor volumes of LNCaP-COX-2 cells xenograft treated with diclofenac or RT alone was $>4$-fold higher than in mice treated with combined diclofenac and radiation $(p<0.05)$.

Conclusions: These in vitro and in vivo findings suggest that conventional COX inhibitor, diclofenac enhances the effect of RT on prostate cancer cells that express COX-2. Thus, diclofenac may have potential as radiosensitizer for treatment of prostate cancer.

Keywords: Prostate cancer, Radiation therapy, COX-2, TRAIL, Apoptosis, Topical therapy, Radiosensitizer, Diclofenac, Radioresistance

*Correspondence: sanai@naramed-u.ac.jp

Department of Urology, Nara Medical University, Nara, Japan 


\section{Background}

Cyclooxygenase (COX; prostaglandin $\mathrm{G} / \mathrm{H}$ synthase, EC 1.14.99.1) is a key enzyme that catalyzes the conversion of arachidonic acid to prostaglandins (PGs) and other prostanoids.

Two isoforms of COX have been identified, COX-1 and COX-2 [1]. Recently, a splicing variant of COX-1 was identified. Alternative splicing generates four different mRNA variants derived from the COX-1 gene - COX-1, COX-3, and two partial COX-1s (PCOX-1 proteins). COX-3 and one of the PCOX-1 proteins (PCOX-1a) are made from the COX-1 gene but retain intron 1 in their mRNAs [2,3]. COX-1, constitutively expressed in almost tissues, is required for homeostatic functions, whereas COX-2, an inducible enzyme, is up-regulated by growth factors, tumor promoters, oncogenes and carcinogens [1,4-6].

Of the two isoforms, COX-2 is consistently upregulated in a number of cancers, including esophagus [7], stomach [8], colon [9], lung [10], pancreas [11], head and neck [12], and prostate [13]. In addition, COX-2 expression is associated with aggressive tumor behavior, worse prognosis and the development of metastatic disease [14].

On immunohistochemical (IHC) staining of prostate, the expression of $\mathrm{COX}-2$ protein in prostate cancer (PCa) was significantly higher than that in benign prostatic hyperplasia $(\mathrm{BPH})$ and normal prostate, while the expression of COX-1 protein was not significantly different between BPH and PCa. Furthermore, the intensity of COX-2 expression increased with increasing tumor grade $[13,15,16]$.

Clinical, and animal studies indicate that the use of aspirin and other non-steroidal anti-inflammatory drugs (NSAIDs) can significantly reduce the risk of colorectal, breast, prostate, lung and esophageal cancer [4,17-19]. As for prostate cancer, recent epidemiological studies indicated that use of aspirin and other NSAIDs reduces the risk of prostate cancer by $20-30 \%$ [20].

A number of studies suggest that COX-2 expression is not only an early event in the carcinogenesis, but is required throughout the entire evolutionary process of cancer development and progression [18]. Furthermore, it has been proposed that COX-2 may regulate the expression of genes that contribute to tumor cell survival, aggressiveness, and angiogenesis. A number of previous studies have shown that PGs can act as potent radioresistant factors of some cancers, and their inhibition resulted in radiosensitization [21-24]. Therefore, COX-2, which induced PGs, is considered to be potential targets for anticancer therapy. Although COX is the only molecular target known of most NSAIDs, both COXdependent and COX-independent mechanism in the apoptotic action of NSAIDs have been reported [25-28].
Diclofenac is a selective COX-1 and COX-2 inhibitor. The reason why we used this drug in this study was that diclofenac was a widely used non-steroidal antiinflammatory drug and topical diclofenac was available.

In the present study, we investigated the role of COX2 expression in radioresistance and the effect of diclofenac on the cell viability and radiosensitivity of prostate cancer cells in vitro experiments. Furthermore, we investigated the efficacy of treatment with topical diclofenac using diclofenac gel in vivo experiment.

\section{Results}

\section{Effect of diclofenac on cell viability of prostate cancer} cells

To evaluate the antitumor potential of diclofenac on cell viability and whether COX-2 expression contributes to cell proliferation, LNCaP-COX-2 cells and LNCaP-Neo were treated with various concentrations of diclofenac for 72 hours.

Diclofenac reduced cell viability in both LNCaP-COX2 cells and LNCaP-Neo in a dose-dependent manner (Figure 1). However, LNCaP-COX-2 cells significantly showed higher sensitivity to diclofenac than LNCaPNeo. Cell viability at $50 \mu \mathrm{M}$ in LNCaP-COX-2 and LNCaP-Neo was $51.6 \%$ and $73.8 \%$, respectively ( $\mathrm{p}<$ 0.0001). The diclofenac $50 \%$ inhibitory concentration (IC50) was calculated in LNCaP-COX-2 and LNCaPNeo and found to be $42.2 \mu \mathrm{M}$ and $91.6 \mu \mathrm{M}$, respectively.

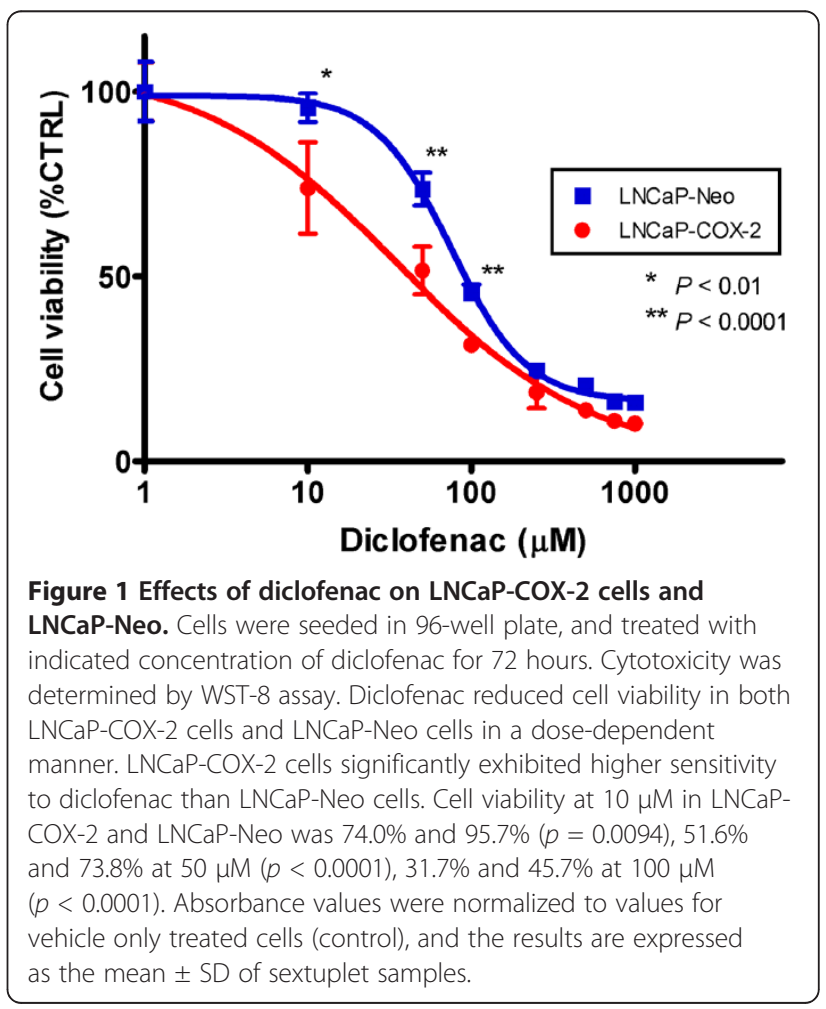


This data suggest that susceptibility to diclofenac may be attributed to the level of COX-2 expression.

\section{Effect of diclofenac on radiosensitivity of prostate cancer cells}

To determine the effect of diclofenac on radiosensitivity of prostate cancer cells, we next examined a clonogenic assay. $\mathrm{LNCaP}-\mathrm{COX}-2$ and $\mathrm{LNCaP}-\mathrm{Neo}$ cells were treated with $10.9 \mu \mathrm{M}$ and $46.7 \mu \mathrm{M}$ (respective IC25 of cell lines) of diclofenac for 48 hours before irradiation $(0,2$ or 4 Gy). The survival fraction of both LNCaP-COX-2 cells and LNCaP-Neo cells was decreased in a radiation dosedependent manner (Figure 2A, 2B). The survival fractions at 2 Gy dose without diclofenac were $78.6 \%$ and $38.2 \%(\mathrm{p}=0.0466)$ for LNCaP-COX-2 and LNCaP-Neo, respectively. LNCaP-COX-2 cells were proved to be more radioresistant than LNCaP-Neo cells. Furthermore, diclofenac significantly sensitized the LNCaP-COX-2 cells to RT. However, this effect was not observed in LNCaP-Neo cells. In LNCaP-COX-2 cells, the survival fractions at 2 Gy dose were $78.6 \%$ and $35.5 \%$ for radiation alone and radiation with diclofenac, respectively ( $\mathrm{p}=0.0225$ ), while the survival fractions were $38.2 \%$ and $30.0 \%$, respectively in $\mathrm{LNCaP}-\mathrm{Neo}(\mathrm{p}=0.4232)$. This data suggested that $\mathrm{COX}-2$ overexpression protected LNCaP-COX-2 cells from the effect of irradiation and that inhibition of COX-2 sensitized to RT.

\section{Diclofenac suppressed RT-induced COX-2 up-regulation} and enhanced the induction of TRAIL

Next, we set out to assess the molecular profile of treated cells using real-time PCR analysis. We focused on

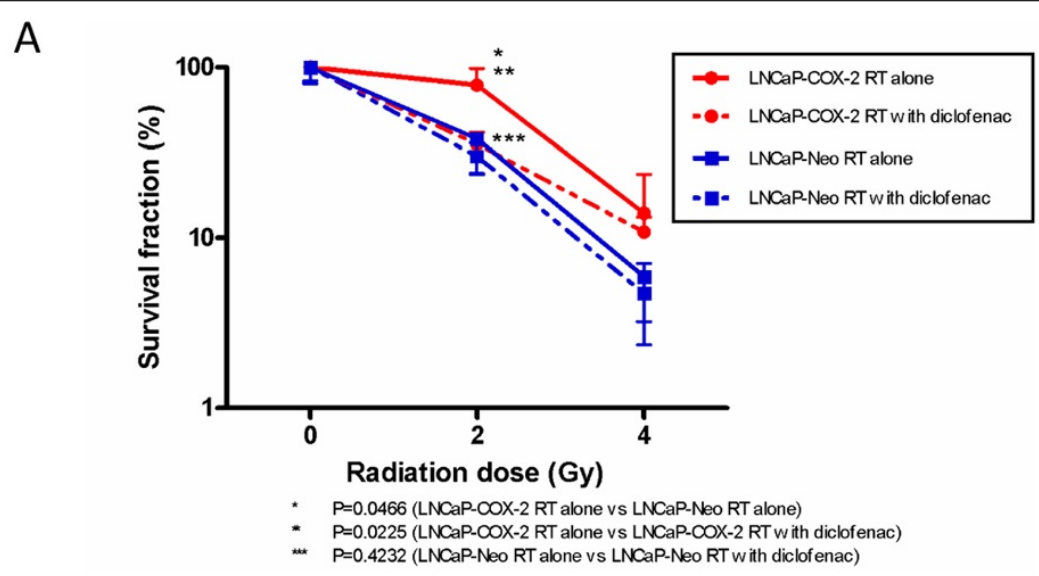

B
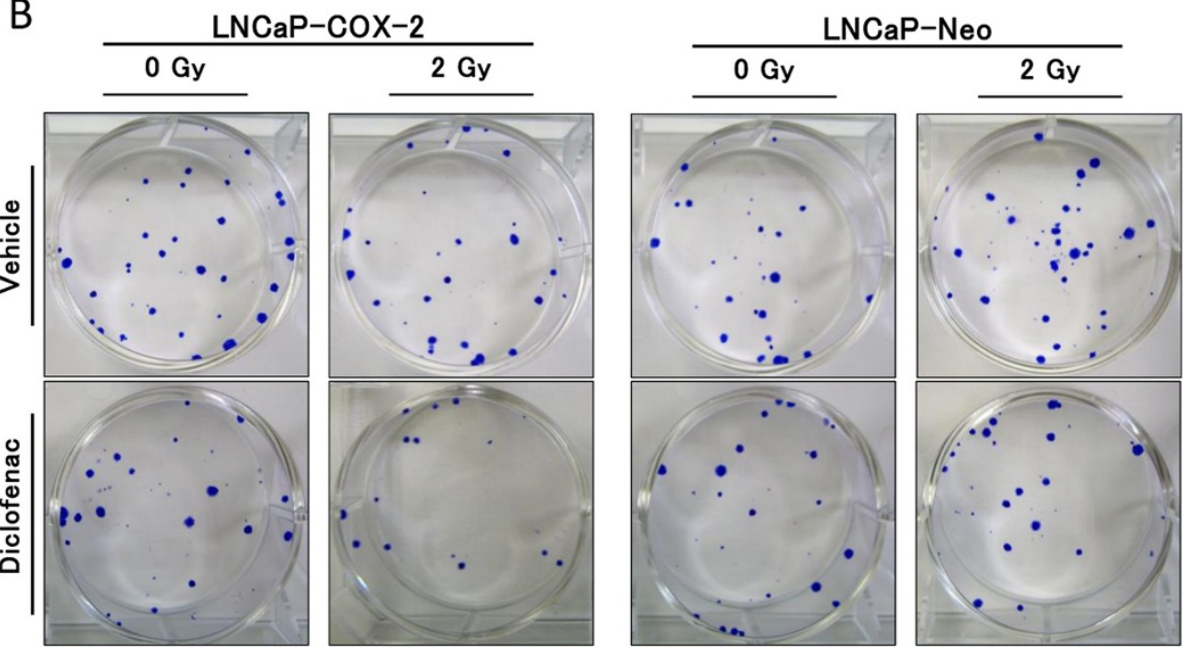

Figure 2 Clonogenic assay for LNCaP-COX-2 and LNCaP-Neo treated with irradiation. Clonogenic assay for LNCaP-COX-2 and LNCaP-Neo treated with irradiation (0, 2 or 4 Gy) with or without diclofenac (IC25). Cells were seeded in 6-well plate, and treated with or without diclofenac for 48 hours, irradiated, and allowed to form colonies. (A) Survival fractions for radiation and diclofenac were normalized by dividing by the survival fractions for untreated cells. LNCaP-COX-2 cells was more radioresistant than LNCaP-Neo cells $(p=0.0225)$. In LNCaP-COX-2 cells, diclofenac enhanced the effect of RT with significant differences between RT alone and RT with diclofenac, when cells were exposed to 2 Gy $(p=0.0466)$. (B) Clonogenic assay of LNCaP-COX-2 cells and LNCaP-Neo cells treated with RT (0, 2 or 4 Gy) and diclofenac (0 or IC25). Photographs of 6-well plates in a representative experiment are shown. 
expression of COX-2 and TRAIL. We investigated the release of TRAIL in response to RT since TRAIL is a most common RT-inducible cytokine [29-31]. In LNCaP-COX-2 cells, RT induced COX-2 up-regulation but diclofenac inhibited RT-induced COX-2 up-regulation (Figure 3A). Furthermore, RT induced TRAIL, and combination with diclofenac enhanced the induction of TRAIL (Figure 3B). Thus, diclofenac made LNCaP-COX-2 cells more sensitive to apoptosis through induction of TRAIL.

\section{Combination of diclofenac and radiation induced apoptosis in LNCaP-COX-2 cells}

According to the results of real-time PCR analysis, TRAIL mRNA expression was found to induce by diclofenac. Consequently, to determine whether the combination of diclofenac and radiation was related with apoptosis, cells were treated with diclofenac (IC50) for 3 hours, thereafter irradiated with 2 Gy. After incubation

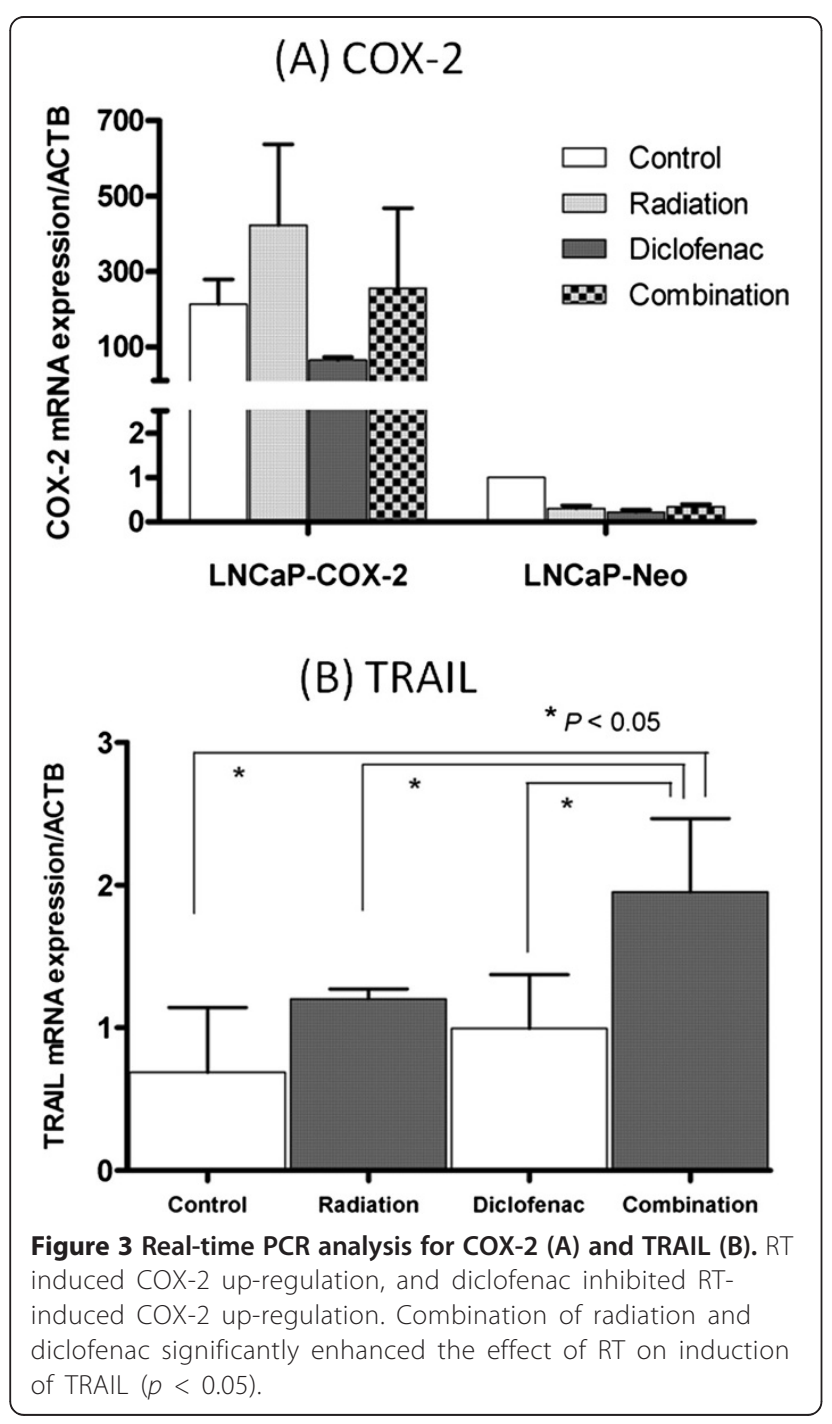

for 3 hours, the cells were harvested to examine apoptosis using Cell Death Detection ELISA ${ }^{\text {Plus }}$ kit according manufacturer's instructions. Apoptosis was not significantly induced in cells treated with either diclofenac alone or radiation alone compared with untreated cells. However, combined treatment of diclofenac and irradiation was significantly induced apoptosis much than untreated cells (Figure 4). This apoptosis was responsible for induction of TRAIL that induced by combined treatment.

Topical treatment with diclofenac reduced tumor growth and enhanced the effect of RT in vivo xenograft mouse model, and suppressed both COX-2 and Ki-67 expression To confirm radiosensitizing effect of diclofenac in vivo, we conducted animal experiments using xenograft mouse model of LNCaP-COX-2. The xenograft mice bearing $\mathrm{LNCaP}-\mathrm{COX}-2$ tumor were treated with topical administration of diclofenac gel onto mice skin with cotton swab once a day with or without irradiation (3 Gy) to the subcutaneous tumor on day 3. Treatment with diclofenac reduced tumor growth to $37.0 \%$ compared to control, whereas treatment with 3 Gy radiation reduced tumor growth to $57.0 \%$ compared to control. The mean relative tumor volumes in control and combined treatment (RT and diclofenac) groups on day 36 were 35.74 fold-change and 5.96, respectively $(\mathrm{p}<0.05)$. In addition, combination therapy resulted in enhanced antitumor potential compared with diclofenac alone or radiation alone (Figure 5A). No weight loss was observed in any of the experimental groups (data not shown).

To investigate the cell proliferation status and level of COX-2 expression in the treated and control tumors, the expression of $\mathrm{Ki}-67$ and COX-2 were analyzed with IHC staining. The expression of COX-2 decreased in

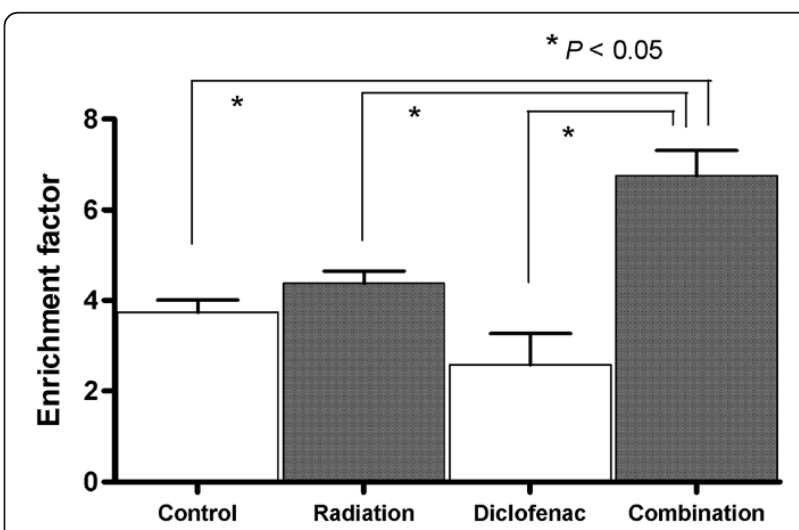

Figure 4 Combined treatment with radiation and diclofenac increased an induction of apoptosis compared with either alone. Cells were incubated for 24 hours, and treated with diclofenac (IC25) for 48 hours, then exposed to radiation (0, 2 Gy). Apoptosis induction was quantified using Cell Death Detection ELISA kit. 


\section{(A)}

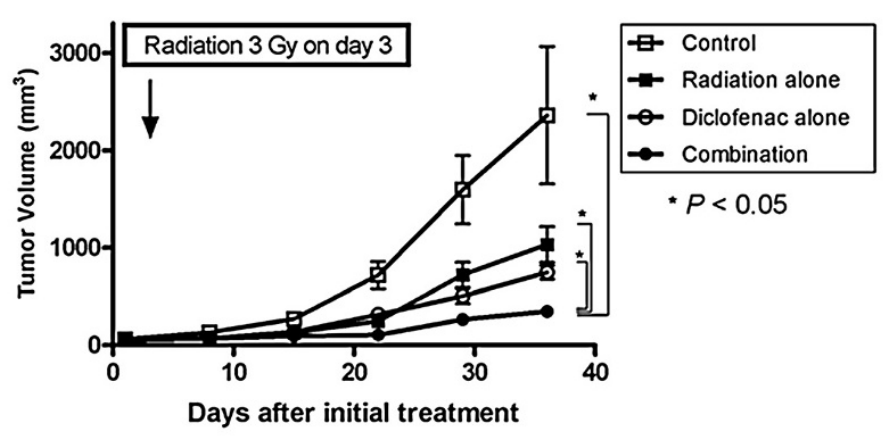

(B)

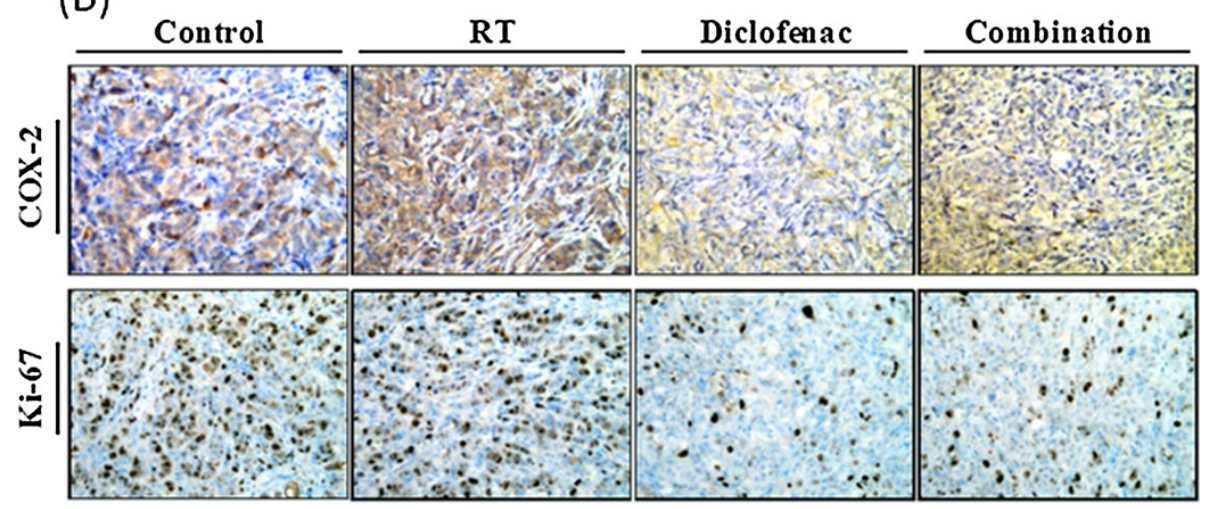

Figure 5 Diclofenac induced the tumor growth delay and enhanced the effect of RT in xenograft mouse model of LNCaP-COX-2. The xenograft mice bearing LNCaP-COX-2 tumor were treated with topical administration of diclofenac gel onto mice skin with cotton swab once a day (day 1-36). The tumors in RT alone group and combination group were exposed to IR with a single dose of 3 Gy on day 3 . Tumor volume was measured with calipers and calculated as $0.52 \mathrm{LW}^{2}$. (A) Tumor volume was significantly reduced in combination group. (B) Immunohistochemical staining for COX-2 and Ki-67 was conducted. The expression of COX-2 decreased in diclofenac group and combination group compared with control group, while the expression of COX-2 increased in RT group. The expression of Ki-67 significantly decreased in diclofenac group and combination group. Original magnification, $\times 200$.

diclofenac group and combination group compared with control group, while the expression of COX-2 increased in RT group. The expression of Ki-67, proliferative index (PI), significantly decreased in diclofenac group (PI: 0.21 ) and combination group (PI: 0.31) compared with control group (PI: 0.61) (Figure 5B).

\section{Discussion}

$\mathrm{PCa}$ is the most common solid tumor in US males and the second leading cause of cancer related deaths [32]. A common treatment option for localized $\mathrm{PCa}$ is RT, which may possess similar survival rates at 5,10 , and 15 -years to radical prostatectomy. Though radiation dose increase has associated with higher cancer control rates, high dose radiation can cause important side effects, such as urinary dysfunction, impotence, and rectal symptoms. Several reports have demonstrated that the addition of androgen deprivation to RT may improved the results of patients with intermediate- and high-risk PCa. However in high-risk patients treated with RT, 5-year recurrence free survival is approximately $50 \%$.
Thus, new molecular targets for the enhancement of $\mathrm{RT}$ and regression of RT adverse event are needed for some patients with localized prostate cancer.

NSAIDs have been demonstrated to potentiate radiosensitivity of cancer cells, and recent studies reported the radiosensitizing effect of selective COX-2 inhibitors on tumor cells [23-25,33].

The cells overexpressing COX-2 tend to be resistant to apoptosis, and COX-2 inhibitors have been shown to induce apoptosis in these types of cells. Therefore, we hypothesized that the COX inhibitor, diclofenac could enhance the effect of radiation on prostate cancer cells that constitutively express COX-2.

Although many of recent studies reported about the relation between COX inhibitor and radiosensitizing effect, conducted chiefly in vitro experiments study. We further attempted to show the potentiation of RT in vivo experiments.

This study is the first evidence that treatment with diclofenac increased the radiosensitivity of prostate cancer cells by suppression of COX-2 up-regulation and induction of TRAIL in vitro, and that topical treatment 
with diclofenac gel enhanced antitumor potential of RT in vivo.

The underlying mechanism responsible for the antitumor effect of COX inhibitor has not been clearly elucidated, although several possibilities have been proposed, i.e. modulation of angiogenesis, regulation of cell cycle, and reverse of PGs-induced immunosuppression [9]. PGs, which were produced by COX-2, have been proposed to promote the proliferation and metastasis of cancer cells and secondarily encourage the growth of cancer cells by immunosuppression. Furthermore, PGE1 and PGE2 are known to induce angiogenesis $[9,18]$. Milas and his colleagues demonstrated that the NSAID indomethacin prolongs tumor growth delay and increases the tumor cure rate after radiotherapy [22,24]. It has been proposed that NSAIDs increased tumor radiation response by lowering the level of PGs in the tumor [23]. Based on recent findings that PGs and COX-2 are radioprotective factors, it is reasonable to assume that diclofenac inhibited tumor cell proliferation and increased tumor radiosensitivity by reducing tumorproducing PGs [34,35]. Recent experiments using selective or not selective COX-2 inhibitor, including celecoxib and NS-398, demonstrated that COX-2 overexpression might be responsible for radioresistance $[6,25]$, and that suppression of COX-2 overexpression render cells susceptible to RT.

NSAIDs have been demonstrated to potentiate the effect of RT on cancer cells in vitro and in vivo, however, no study has reported on the efficacy of topical diclofenac gel.

In this study, we investigated the antitumor potential and the radiosensitizing effect of diclofenac on prostate cancer cells. In LNCaP-COX-2 cells, diclofenac significantly reduced the cell viability and sensitized to RT. COX-2 overexpression is responsible for radioresistance in clonogenic assay. $\mathrm{LNCaP}-\mathrm{COX}-2$ cells were more susceptible to diclofenac than LNCaP-neo cells. These findings suggested that LNCaP-COX-2 might be addictive to COX-2 than LNCaP-Neo cells, and that COX-2 might be one of survival factors for LNCaP-COX-2 cells. We first showed that the combination of RT and topical treatment with diclofenac gel significantly induced the tumor growth delay than either treatment alone in prostate cancer tumor in vivo. The radiosensitizing effect of diclofenac was not observed in LNCaPNeo cells that lacked COX-2 expression.

In real-time PCR analysis, RT induced TRAIL and combination with diclofenac enhanced the RTinduced TRAIL.

We first suggested that additional aspects of the COX inhibitor, diclofenac-induced potentiation of tumor radioresponse were caused by the induction of TRAIL.
TRAIL is an identified member of the TNF ligand family that can induce a rapid caspase-dependent apoptosis with high specificity for malignant cells.

Recent study has been shown that significant release of TNF-related apoptosis inducing ligand was observed in response to ionizing radiation(IR) in lung cancer cells [36], and that IR up-regulates TRAIL-Receptor surface expression [37]. TNF- $\alpha$ and TRAIL are directly involved in apoptosis and are induced by IR [38]. Irradiation induced release of tumor necrosis factor- $\alpha$, or TRAIL [36].

Our findings that RT significantly induced TRAIL in real-time PCR analysis are consistent with these results. In addition, combination of RT and diclofenac significantly increased the induction of TRAIL compared with either alone. The enhancement of TRAIL can explained the observed increase of apoptosis.

Apoptosis is controlled via two major pathways, including one that originates at the cell membrane and another that involves the mitochondria. The membrane death receptor (DR) pathway involves DRs such as Fas, TNF-R1, DR-3, DR-4, and DR-5, that are activates by their respective ligands and engages the intracellular apoptotic machinery. In addition, caspase pathway is involved in TRAIL-induced cell death, and IR-induced TRAIL contributed to cell death via increase of caspase8, caspase-9, and caspase- 3 activation. COX-2 expression has shown to significantly attenuate TRAIL-induced caspase- 8 , caspase- 9 , and caspase- 3 [31]. NSAIDs, sulindac sulfide, increased both DR-4 and DR-5 mRNA levels. Modulation of the level of DR- 5 regulated the apoptotic response to TRAIL [31]. RT induced TRAIL in both LNCaP-COX-2 and LNCaP-Neo cells (data not shown) in real time PCR analysis. COX-2 overexpression was shown to attenuate the effect of TRAIL-induced apoptosis and reduce Fas-mediated apoptosis [31,39].

\section{Conclusions}

This study reveals that COX-2 is a surviving factor associated with radiation resistance. Diclofenac sodium suppressed COX-2, induced by irradiation, which rendered cells resistant to RT. In addition, combination therapy of RT plus diclofenac enhanced the expression of TRAIL, and therefore induced apoptosis in prostate cancer cells compared with RT or diclofenac alone. These findings suggest that diclofenac may be the effective radiosensitizer against human prostate cancer overexpressed COX-2.

\section{Methods}

\section{Chemical compounds and reagents}

A selective COX-1 and COX-2 inhibitor, diclofenac sodium (diclofenac), was purchased from Sigma-Aldrich (St Louis, MO, USA). For in vitro studies, diclofenac was 
dissolved in distilled water at a stock concentration of $50 \mathrm{mM}$ and this stock was diluted in media just before use. For in vivo studies, diclofenac sodium 1\% topical gel was purchased from Novartis Pharma AG (Basel, Switzerland).

\section{Cell culture and transfection}

The human prostate cancer cell line $\mathrm{LNCaP}$ was purchased from American Type Culture Collection (Manassas, VA, USA) and was maintained in RPMI 1640 supplemented with $10 \%$ fetal bovine serum, penicillin-streptomycin (100 units $/ \mathrm{ml}$ and $10 \mu \mathrm{g} / \mathrm{ml}$ ) in a standard incubator at $37^{\circ} \mathrm{C}$ with $5 \% \mathrm{CO}_{2}$.

LNCaP-COX-2 cells, stably transfected to overexpress COX-2, and LNCaP-Neo cells as the control were kindly provided by Dr. Astushi Mizokami (Kanazawa, Japan).

\section{Irradiation procedures}

To determine sensitivity to irradiation, plated prostate cells were exposed to radiation dose using a MBR-1520R X-ray unit (Hitachi Medical Co., Tokyo, Japan). The irradiation for in vivo experiments was described later.

\section{In vitro cell viability assay}

Cells were seeded in a 96-well plate at a density of 2,000 cells per well in growth media and incubated for 24 hours. They were treated with various concentrations of diclofenac sodium ranging from 0$1000 \mu \mathrm{M}$. After incubating the plates for 48 hours, cell viability was determined using a Cell Counting Kit-8 (Dojindo Labor-atories, Kumamoto, Japan) according to the manufacturer's instructions. The viability index was expressed by relative value to the untreated cells. Each assay was performed in sextuplet. Dose response curves were generated. The data are expressed as means \pm standard deviations (SD).

\section{Clonogenic assay}

Cells were seeded in a 6-well plate at a density of $10 \times 10^{4}$ cells per well in growth medium, and incubated for 24 hours. Then the cells were treated with $25 \%$ inhibitory concentration (IC25) of diclofenac sodium for 48 hours and the plates were exposed to 0-4 Gy radiation. Immediately after irradiation, the cells were trypsinized, serial diluted and seeded into 6-well plates. The plates were incubated for 14 days to allow colony formation. The colonies were stained with $0.25 \%$ crystal violet in ethanol and counted by eye with a cutoff of 50 viable cells. The survival fraction was calculated relative to non-irradiated cells. Data were shown as means \pm SD.

\section{Real-time PCR analysis}

Total RNA was extracted from cells using a QIAamp RNA Blood Mini kit according the manufacturer's instructions (Qiagen, Valencia, CA, USA). RNA concentrations were determined by UV spectrophotometer, and $2 \mu \mathrm{g}$ of total RNA was reverse transcribed into cDNA using the High Capacity cDNA Reverse Transcription Kit (Applied Biosystems, Foster City, CA, USA). Realtime PCR was performed on a StepOne Plus ${ }^{\mathrm{TM}}$ Real-time PCR system (Applied Biosystems) with Fast SYBR Green Master Mix (Applied Biosystems). The PCR primer used in this study were: $A C T B$ forward $5^{\prime}$-CTGGAACGGT GAAGCTGACA- $3^{\prime}$ and reverse $5^{\prime}$-CGGCCACATTGT GAACTTTG-3', COX-2 forward 5'-TGCATTCTTTGC CCAGCACT- $3^{\prime}$ and reverse $5^{\prime}$-AAAGGCGCAGTTTAC GCTGT-3', TRAIL forward 5'-GAAGCAACACATTGT CTTCTCCAA-3' and reverse 5'-TTGCTCAGGAAT GAATGCCC-3'.

The results were analyzed with the StepOne Software version 2.0 (Applied Biosystems), using $\beta$-actin gene expression as an internal control.

\section{Apoptosis measurement with cell death detection ELISA $^{\text {Plus }}$ assay}

The Cell Death Detection ELISA ${ }^{\text {Plus }}$ kit (Roche Molecular Biochemicals, Mannheim, Germany) was used to measure DNA fragmentation as a marker for apoptosis according to the manufacturer's instructions.

Briefly, cells were seeded in 96-well plate at a density of 2,000 cells per well, and incubated for 24 hours. Consequently, the cells were treated with diclofenac sodium concentration (IC25) for 48 hours and the plates were exposed to 0-2 Gy radiation.

Cytoplasmic fractions of control and treated cells were transferred into streptavidin-coated 96-well plates and incubated with biotinylated mouse anti-histone antibody and peroxidase-conjugated mouse anti-DNA antibody at room temperature for 2 hours. The rate of apoptosis was determined by measurement at $405 \mathrm{~nm}$ using a microplate reader. The enrichment of mono- and oligonucleosomes released into the cytoplasm was calculated using the following formula: enrichment factor $=$ absorbance of sample cells/absorbance of control cells.

\section{Xenograft mouse model and administration of diclofenac and IR}

Male BALB/c nu/nu mice were purchased from Charles River Japan, Inc. (Yokohama, Japan). The mice were maintained under specific pathogen-free conditions and provided with sterile food and water, and used at 68 weeks of age. All animal protocols for this experiment were approved by the Animal Care Committee of the Nara Medical University in accordance with the policies established in the NIH Guide for the care and use of laboratory animals.

LNCaP-COX-2 cells $\left(5 \times 10^{6}\right.$ cells $)$ in $0.05 \mathrm{ml}$ of RPMI medium, together with of $0.05 \mathrm{ml}$ of Matrigel (Becton 
Dickson, Bedford, MA, USA), were injected subcutaneously into the bilateral flanks of each mouse. When the tumors reached $0.5 \mathrm{~cm}$ in diameter, the animals were divided randomly into four groups (control, diclofenac only, radiation only, diclofenac and radiation) ( $\mathrm{n}=6$ for each group) and treatment was initiated (Day 1).

In the treated groups, diclofenac sodium $1 \%$ gel was applied daily to the skin overlying the tumors with a cotton swab. At day 3, the mice were irradiated with 3 Gy dose using MBR-1520R X-ray unit. Only tumors treated with irradiation were left exposed. All other regions of the mice were shielded with lead. The tumor sizes and volumes were measured once a week with calipers, and the tumor volumes were calculated using the formula: $0.52 \times($ Length $) \times(\text { Width })^{2}$.

\section{Immunohistochemical (IHC) staining}

The resected tumors were fixed in $10 \%$ buffered formalin, embedded in paraffin, and sectioned (3- $\mu \mathrm{m}$ thickness). IHC staining for COX-2 and Ki-67 was conducted as follows: slides were deparaffinized and incubated for $5 \mathrm{~min}$ with $3 \% \mathrm{H}_{2} \mathrm{O}_{2}$ to quench the endogenous peroxidase activity. Antigen retrieval was performed for $10 \mathrm{~min}$ in citrate buffer with autoclave treatment. Slides were incubated with primary antibody at $4^{\circ} \mathrm{C}$ overnight. Next, the tissue sections were incubated with mouse monoclonal anti-human COX-2 antibody (Santa Cruz, USA) and mouse monoclonal anti-human Ki-67 antibody (Dako, Glostrup, Denmark). Sections were then developed with diaminobenzidine (DAB), counterstained with hematoxylin, dehydrated, and mounted.

The Ki-67 proliferative index was defined as the proportion of Ki-67-positive tumor cells to the total tumor cells.

\section{Statistics}

In in vitro experiments, differences between means were compared by the Student's t-test. A $p$-value of 0.05 or less between groups was considered significant. Data were shown as means \pm Standard deviations. In the analysis of in vivo experiments, statistical differences between the relative volumes in the treated and control groups were analyzed using Mann-Whitney $\mathrm{U}$ test (statistical tests were two-sided). A $p$-value of less than 0.05 was considered statistically significant.

\section{Competing interests}

The authors declare that they have no competing interests.

\section{Authors' contributions}

$\mathrm{TI}$ and SA conceived the experiments. $\mathrm{TI}$ and $\mathrm{SO}$ conducted the experiments and analyzed the data together with SA. ST, AH, KF and $\mathrm{YH}$ supervised the experiments and the writing of the manuscript. All authors read and approved the final version of the manuscript.

\section{Acknowledgements}

This work was supported by Department of Urology in Nara Medical University.

Received: 18 August 2012 Accepted: 27 December 2012

Published: 5 January 2013

\section{References}

1. Rouzer CA, Marnett LJ: Cyclooxygenases: structural and functional insights. J Lipid Res 2009, 50(Suppl):S29-S34.

2. Chandrasekharan NV, Dai H, Roos KL, Evanson NK, Tomsik J, Elton TS, Simmons DL: COX-3, a cyclooxygenase- 1 variant inhibited by acetaminophen and other analgesic/antipyretic drugs: cloning, structure, and expression. Proc Natl Acad Sci USA 2002, 99:13926-13931.

3. Schwab JM, Beiter T, Linder JU, Laufer S, Schulz JE, Meyermann R, Schluesener HJ: COX-3 a virtual pain target in humans? FASEB J 2003, 17:2174-2175.

4. Gupta RA, Dubois RN: Colorectal cancer prevention and treatment by inhibition of cyclooxygenase-2. Nat Rev Cancer 2001, 1:11-21.

5. Williams CS, Mann M, Dubois RN: The role of cyclooxygenases in inflammation, cancer, and development. Oncogene 1999, 18:7908-7916.

6. Smith WL, DeWitt DL, Garavito RM: Cyclooxygenases: structural, cellular and molecular biology. Annu Rev Biochem 2000, 69:145-182.

7. Zimmermann KC, Sarbia M, Weber AA, Borchard F, Gabbert HE, Schrör K Cyclooxygenase-2 expression in human esophageal carcinoma. Cancer Res 1999, 59:198-204.

8. Ristimäki A, Honkanen N, Jänkälä H, Sipponen P, Härkönen M: Expression of cyclooxygenase-2 in human gastric caricinoma. Cancer Res 1997, $57: 1276-1280$

9. Sano H, Kawahito Y, Wilder RL, Hashiramoto A, Mukai S, Asai K, Kimura S, Kato $\mathrm{H}$, Kondo M, Hla T: Expression of cyclooxygenase-1 and -2 in human colorectal cancer. Cancer Res 1995, 55:3785-3789.

10. Hida T, Yatabe Y, Achiwa H, Muramatsu H, Kozaki K, Nakamura S, Ogawa M, Mitsudomi T, Sugiura T, Takahashi T: Increased expression of cyclooxygenase 2 occurs frequently in human lung cancers, specifically in adenocarcinomas. Cancer Res 1998, 58:3761-3764.

11. Tucker ON, Dannenberg AJ, Yang EK, Zhang F, Teng L, Daly JM, Soslow RA, Masferrer JL, Woerner BM, Koki AT, Fahey TJ 3rd: Cyclooxygenase-2 expression is up-regulated in human pancreatic cancer. Cancer Res 1999, 59:987-990

12. Chan G, Boyle JO, Yang EK, Zhang F, Sacks PG, Shah JP, Edelstein D, Soslow RA, Koki AT, Woerner BM, Masferrer JL, Dannenberg AJ: Cyclooxygenase-2 expression is up-regulated in squamous cell carcinoma of the head and neck. Cancer Res 1999, 59:991-994.

13. Gupta S, Srivastava M, Ahmad N, Bostwick DG, Mukhtar H: Over-expression of cyclooxygenase-2 in human prostate adenocarcinoma. Prostate 2000, 42:73-78.

14. Zhang H, Sun XF: Overexpression of cyclooxygenase-2 correlates with advanced stages of colorectal cancer. Am J Gastroenterol 2002, 97:1037-1041.

15. Madaan S, Abel PD, Chaudhary KS, Hewitt R, Stott MA, Stamp GW, Lalani EN: Cytoplasmic induction and over-expression of cyclooxygenase-2 in human prostate cancer: implications for prevention and treatment. BJU Int 2000, 86:736-741.

16. Yoshimura R, Sano H, Masuda C, Kawamura M, Tsubouchi Y, Chargui J, Yoshimura N, Hla T, Wada S: Expression of cyclooxygenase-2 in prostate carcinoma. Cancer 2000, 89:589-596.

17. Harris RE, Alshafie GA, Abou-lssa H, Seibert K: Chemoprevention of breast cancer in rats by celecoxib, a cyclooxygenase 2 inhibitor. Cancer Res 2000, 60:2101-2103.

18. Harris RE: Cyclooxygense-2 (cox-2) blockade in the chemoprevention of cancers of the colon, breast, prostate, and lung. InflammoPharmacology 2009, 17:55-67.

19. Roberts RO, Jacobson DJ, Girman CJ, Rhodes T, Lieber MM, Jacobsen SJ: A population-based study of daily nonsteroidal antiinflammatory drug use and prostate cancer. Mayo Clin Proc 2002, 77:219-225

20. Jacobs EJ, Rodriguez C, Mondul AM, Connell CJ, Henley SJ, Calle EE, Thun $\mathrm{MJ}$ : A large cohort study of aspirin and other nonsteroidal antiinflammatory drugs and prostate cancer incidence. J Natl Cancer Inst 2005, 97:975-980. 
21. Vane JR: Inhibition of prostaglandin synthesis as a mechanism of action for aspirin-like drugs. Nat New Biol 1971, 231:232-235.

22. Milas L, Kishi K, Hunter N, Mason K, Masferrer JL, Tofilon PJ: Enhancement of tumor response to gamma-radiation by an inhibitor of cyclooxygenase-2 enzyme. J Natl Cancer Inst 1999, 91:1501-1504.

23. Furuta $Y$, Hunter $N$, Barkley $T \mathrm{Jr}$, Hall E, Milas L: Increase in radioresponse of murine tumors by treatment with indomethacin. Cancer Res 1988, 48:3008-3013

24. Milas L, Furuta Y, Hunter N, Nishiguchi L, Runkel S: Dependence of indomethacin-induced potentiation of murine tumor radioresponse on tumor host immunocompetence. Cancer Res 1990, 50:4473-4477.

25. Anai S, Tanaka M, Shiverick KT, Kim W, Takada S, Boehlein S, Goodison S, Mizokami A, Rosser CJ: Increased expression of cyclooxygenase-2 correlates with resistance to radiation in human prostate adenocarcinoma cells. J Urol 2007, 177:1913-1917.

26. Piazza GA, Rahm AL, Krutzsch M, Sperl G, Paranka NS, Gross PH, Brendel K, Burt RW, Alberts DS, Pamukcu R, Ahnen DJ: Antineoplastic drugs sulindac sulfide and sulfone inhibit cell growth by inducing apoptosis. Cancer Res 1995, 55:3110-3116

27. Tsujii M, DuBois RN: Alterations in cellular adhesion and apoptosis in epithelial cells overexpressing prostaglandin endoperoxide synthase 2 . Cell 1995, 83:493-501.

28. Hanif R, Pittas A, Feng Y, Koutsos MI, Qiao L, Staiano-Coico L, Shiff SI, Rigas B: Effects of nonsteroidal anti-inflammatory drugs on proliferation and induction of apoptosis in colon cancer cells by a prostaglandinindependent pathway. Biochem Pharmacol 1996, 52:237-245.

29. Ahmed MM, Sells SF, Venkatasubbarao K, Fruitwala SM, Muthukkumar S, Harp C, Mohiuddin M, Rangnekar VM: Ionizing radiation-inducible apoptosis in the absence of p53 linked to transcription factor EGR-1. J Biol Chem 1997, 272:33056-33061.

30. Marini P, Schmid A, Jendrossek V, Faltin H, Daniel PT, Budach W, Belka C: Irradiation specifically sensitizes solid tumour cell lines to TRAIL mediated apoptosis. BMC Cancer 2005, 14:5

31. Tang X, Sun YJ, Half E, Kuo MT, Sinicrope F: Cyclooxygenase-2 overexpression inhibits death receptor 5 expression and confers resistance to tumor necrosis factor-related apoptosis-inducing ligand-induced apoptosis in human colon cancer cells. Cancer Res 2002, 62:4903-4908.

32. Jemal A, Siegel R, Xu J, Ward E: Cancer statistics, 2010. CA Cancer J Clin 2010, 60:277-300.

33. Pyo H, Choy H, Amorino GP, Kim J, Cao Q, Hercules SK, DuBois RN: A selective cyclooxygenase-2 inhibitor, NS-398, enhances the effect of radiation in vitro and in vivo preferentially on the cells that express cyclooxygenase-2. Clin Cancer Res 2001, 7:2998-3005.

34. Hanson WR, Ainsworth EJ: 16,16-Dimethyl prostaglandin E2 induces radioprotection in murine intestinal and hematopoietic stem cells. Radiat Res 1985, 103:196-203.

35. Walden TL Jr, Patchen M, Snyder SL: 16,16-Dimethyl prostaglandin E2 increases survival in mice following irradiation. Radiat Res 1987, 109:440-448.

36. Shareef MM, Cui N, Burikhanov R, Gupta S, Satishkumar S, Shajahan S, Mohiuddin M, Rangnekar VM, Ahmed MM: Role of tumor necrosis factoralpha and TRAIL in high-dose radiation-induced bystander signaling in lung adenocarcinoma. Cancer Res 2007, 67:11811-11820.

37. Johnson GE, Ivanov VN, Hei TK: Radiosensitization of melanoma cells through combined inhibition of protein regulators of cell survival. Apoptosis 2008, 13:790-802

38. Unnithan J, Macklis RM: TRAIL induction by radiation in lymphoma patients. Cancer Invest 2004, 22:522-525.

39. Nzeako UC, Guicciardi ME, Yoon JH, Bronk SF, Gores GJ: COX-2 inhibits Fasmediated apoptosis in cholangiocarcinoma cells. Hepatology 2002, 35:552-559.

doi:10.1186/1471-2490-13-1

Cite this article as: Inoue et al: Inhibition of COX-2 expression by topical diclofenac enhanced radiation sensitivity via enhancement of TRAIL in human prostate adenocarcinoma xenograft model. BMC Urology 2013 13:1.

\section{Submit your next manuscript to BioMed Central and take full advantage of:}

- Convenient online submission

- Thorough peer review

- No space constraints or color figure charges

- Immediate publication on acceptance

- Inclusion in PubMed, CAS, Scopus and Google Scholar

- Research which is freely available for redistribution

Submit your manuscript at www.biomedcentral.com/submit
C Biomed Central 